\title{
PENGARUH IKLIM TROPIS LEMBAB TERHADAP KERUSAKAN FASADE BANGUNAN KOLONIAL DI KOTA LAMA SEMARANG
}

\author{
Gagoek Hardiman ${ }^{1}$, Sukawi ${ }^{2}$, Satriya Wahyu Firmandhani ${ }^{3}$ \\ 1,2,3 Jurusan Arsitektur Fakultas Teknik, Universitas Diponegoro Semarang \\ Jl. Prof Sudarto SH Tembalang Semarang 50131
}

\begin{abstract}
ABSTRAK
Kota Lama Semarang sebagai kawasan bangunan Kolonial Belanda, merupakan kawasan Cagar Budaya yang wajib dilestarikan dan dilindungi keberadaanya. Upaya pelestarian yang dilakukan dari berbagai pihak telah menunjukkan hasil dengan aktif dan terawatnya beberapa bangunan kolonial disana. Namun masih terdapat pula sejumlah bangunan yang berkondisi buruk. Kondisi bangunan yang rawan roboh, fasade bangunan yang rusak dengan cat yang mengelupas dan ditumbuhi tanaman liar. Hal itu merupakan bentuk pengaruh alami dari iklim di Indonesia. Menyikapi fenomena tersebut, penelitian ini bertujuan untuk mengetahui sejauh mana pengaruh iklim tropis lembab terhadap kerusakan fasade bangunan kolonial tersebut dengan metoda deskriptif kualitatif. Lokus penelitian difokuskan pada bangunan di koridor jl. Letjen Suprapto.

Sebagian besar bangunan kolonial di Kota Lama Semarang telah direnovasi dan difungsikan kembali. Namun ada pula sejumlah bangunan yang tidak difungsikan, tidak terawat hingga rawan roboh dan bahkan sudah roboh. Begitu pula kondisi bangunan yang ada di Jl. Letjen Suprapto. Sebagian bangunan yang direnovasi masih mempertahankan bentuk awalnya (khas bangunan kolonial) dan difungsikan sebagai bangunan komersial. Kondisi fasade bangunan juga diperbaharui sehingga memperindah citra kawasan. Namun terdapat pula fasade bangunan yang tidak diperbaharui walaupun bangunan difungsikan kembali. Fasade bangunan tersebut berkondisi buruk dengan cat yang usang, mengelupas dan ditumbuhi tanaman liar. Sama halnya dengan bangunan yang tidak direnovasi dan tidak difungsikan. Kondisinya rawan roboh dan fasade bangunan usang tak terawat.

Dalam pengamatan dari luar bangunan, dapat disimpulkan bahwa rusaknya fasade bangunan-bangunan kolonial di koridor jl. Letjen. Suprapto disebabkan kurangnya upaya perawatan sehingga elemen yang rusak karena lapuk disebabkan kondisi yang lembab, atau terkena air hujan selama bertahun tahun, tidak segera diatasi dengan perawatan yang memadai atau dengan penggantian elemen yang rusak dengan meterial yang sama tampilan arsitekturnya.
\end{abstract}

Kata Kunci: Pelestarian, Bangunan Kolonial, Tropis

\section{PENDAHULUAN}

Kota Lama Semarang saat ini merupakan salah satu ikon penting kota Semarang. Bangunan-bangunan kuno dengan arsitektur kolonial Belanda masih mendominasi kawasan tersebut.

Beberapa bangunan telah ditentukan sebagai cagar budaya, berdasarkan Perda no 8 tahun 2003 tentang RTBL Kawasan Kota Lama Semarang juga telah disusun mengenai segala pedoman pengembangan kawasan Kota Lama. Pemerintah Kota Semarang, telah mencanangkan agenda khusus untuk kota lama. Antara lain: rencana pelaksanaan Holland Festival dan Simfoni Kota Lama yang akan digelar secara regular, car free night, pameranpameran dan pasar benda antik (Widiastuti, 2014)

Kawasan Kota lama dulu merupakan kawasan perdagangan di abad ke-18. Dengan luas area kurang lebih seluas 31 hektar (Jonki Tio, 2012). Sesuai karakteristik bangunan dan lingkungan yang masih mencerminkan suasanaa arsitektur Belanda maka kawasan kota lama Semarang dijuluki; The Little Netherland (Purwanto, 1996).

Salah satu jalan yang terdapat di Kota lama Semarang adalah Jl. Letjen Suprapto yang memiliki letak dan peran yang strategis karena terdapat sejumlah bangunan Kolonial Belanda yang terekspos ditepi jalan tersebut.

Kondisi bangunan kolonial di Kota Lama telah banyak yang direnovasi dan difungsikan kembali, dan ada pula yang tidak difungsikan dan terbengkalai (Sari, 2015). Beberapa bangunan kuno di sepanjang jalan Letjen Suprapto telah direnovasi dan dilestarikan dengan tetap mempertahankan bentuk aslinya antara lain sekarang difungsikan untuk rumah makan antara lain Ikan Bakar Cianjur, Spiegel Bistro, Teko Deko 
Cafe, dan lain-lain. Namun beberapa justru dirobohkan dan dalam proses pembusukan.

Oleh karena itu sangat perlu diadakan penelitian untuk mengetahui tingkat kerusakan bangunan yang belum direnovasi secara khusus. Untuk tahap awal penelitian karena sulitnya akses ke dalam bangunan. Dilaksanakan terlebih dahulu pengamatan kerusakan fasade bangunan.

Desain bangunan di kota lama secara bertahap telah memperhatikan kondisi dan situasi iklim tropis lembab (Purwanto. 1996). Hal itu dikarenakan pengguna bangunan Kota Lama semakin menyadari dan secara alamiah mengantisipasi gangguan iklim yang belum diakomodir dalam desain bangunan kolonial. Karena produk arsitektur sangat dipengaruhi oleh kondisi iklim setempat (Rapoport, 1969)

Namun karena usia bangunan yang sudah tua dan tentu karena iklim di Indonesia yang memiliki kelembaban yang tinggi, curah hujan dan panas matahari yang juga mempengaruhi kondisi fasade bangunan.

Penelitian kondisi kerusakan bangunansangat diperlukan. Karena bangunan kuno yang tidak terawat sewaktu waktu bisa roboh dan membahayakan. Sehingga penelitian tingkat kerusakan sangat diperlukan agar dapat diketahui solusi perbaikannya agar bangunan tetap dapat berdiri dengan kokoh.

Setelah Badan Pengelola Kawasan Kota Lama (BPK2L) menyatakan ada 8 bangunan tua di kota lama yang roboh (Budaya, Rimanews.com). Pada tgl 24 November 2013 bangunan kuno di jalan Merak roboh dengan menelan 1 korban (Sindonews.com). Pada 25 Desember 2015 gedung bekas kantor redaksi surat kabar Belanda de Locomotief juga roboh (Kompas.com).

Penelitian kondisi fasade bangunan merupakan salah satu usaha untuk melestarikan bangunan kuno yang terdapat di kawasan kota lama.

\section{METODE PENELITIAN}

Penelitian menggunakan metoda deskriptif kualitatif, dengan mengambil lokus analisis $\mathrm{Jl}$. Letjen Suprapto Semarang. Jalan Letjen Suprapto menjadi lokus analisis penelitian karena sudah merepresentasikan sebagian besar bangunan kolonial di Kota Lama Semarang.
Penelitian dilaksanakan dalam empat tahap kegiatan, sebagai berikut:

\section{- Tahap1 - Observasi}

Merupakan kegiatan survei, yang mencakup survey lapangan (primer), lingkungan, tapak dan bangunan dan survei data sekunder serta kajian referensi. Observasi dilakukan pada awal kegiatan untuk mengidentifikasi kondisi eksisting bangunan/kawasan kota lama Semarang.

Output dari survey untuk mengetahui tampilan fasade bangunan dan penyelesaian desain yang dapat menghambat laju aliran panas agar tidak masuk kedalam bangunan.

Output proses ini adalah teridentifikasinya bagian-bagian kondisi bangunan dan lingkungan dari aspek disiplin arsitektur seperti: ukuran bangunan, detail material bangunan, jarak bangunan dengan bangunan sekitar, bentuk fasade, ruang terbuka disekelilingnya, serta kondisi fisik (struktur, dan komponen bangunan).

\section{-Tahap 2 - Dokumentasi \& Gambar Eksisting}

Pendeskripsian kondisi lapangan fasade bangunan di Kota Lama berikut dengan lingkungan sekitarnya berkenaan dengan fisika bangunan, lingkungan dan perkotaan. Pada tahap ini akan dihasilkan data-data yang terkait dengan masalah teknis berupa dokumentasi foto. Sesuai dengan lingkup kajian berdasarkan pendekatan disiplin arsitektur maka kajian teknis yang dilakukan meliputi: penilaian terhadap material bangunan, yang akan memberikan gambaran terhadap tampilan fasade dan kondisi bangunan/komplek bangunan.

\section{- Tahap 3 - Analisis Kerusakan fasade karena Kelembaban Tinggi}

Analisis, menggunakan metoda saintifik, berkenaan dengan keteknikan, fisik objek, material dan arsitektural. Pada tahap ini perlakuan data-data yang telah terkumpul baik melalui studi pustaka dan survei, diklasifikasikan dan dikategorisasi, kemudian dianalisa dengan tingkat kerusakan pada tampilan fasade. Hasil analisis ini untuk memperoleh kesimpulan penelitian. 


\section{- Tahap 4 - Strategi dan Implementasi}

Strategi dan implementasi: menyangkut strategi untuk mendesain dengan memperhatikan iklim setempat diantaranya sinar matahari yang membawa panas dan tampias curah hujan. Termasuk menyusun rekomendasi yang dapat digunakan untuk memberi arahan bagi semua pihak yang terlibat pelestarian penataan serta restorasi bangunan pada bangunan sepanjang jl Letjen Suprapto pada khususnya dan kawasan kota lama pada umumnya.

\section{HASIL DAN PEMBAHASAN}

Berdasarkan hasil olah data primer, kondisi eksisting bangunan di Jl. Letjen Suprapto dapat dibagi dalam 2 kategori:

\section{- Bangunan dengan karakter asli kolonial}

Bangunan dengan karakter asli kolonial masih banyak ditemui di Jl. Letjen Suprapto dengan kondisi fasade bangunan yang beragam.

Bangunan-bangunan dimanfaatkan untuk perkantoran, restoran, bank, namun ada pula yang tidak difungsikan.
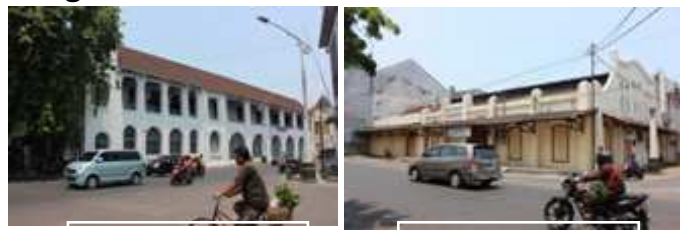

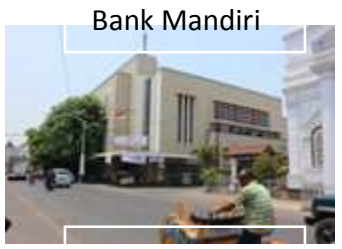

Perkantoran

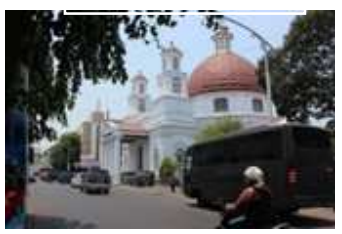

Gereja

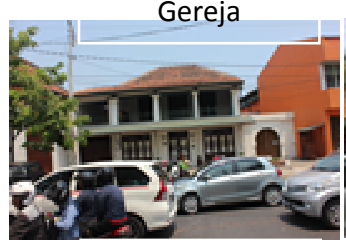

Cafe

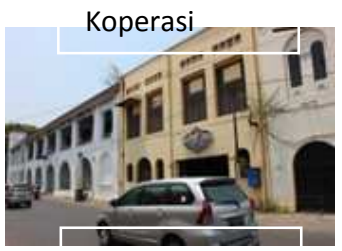

Restoran
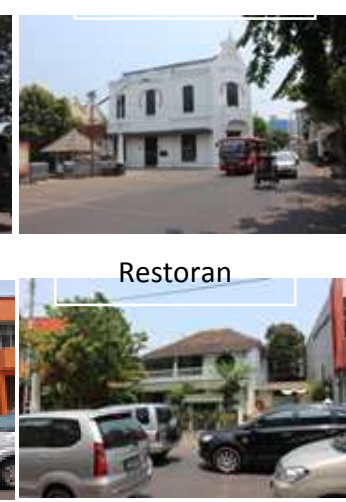

Hotel

Gambar 1.Kondisi \& fungsi bangunan kolonial dengan karakter asli sisi utara Jl. Letjen Suprapto Sumber: Penulis (2015)

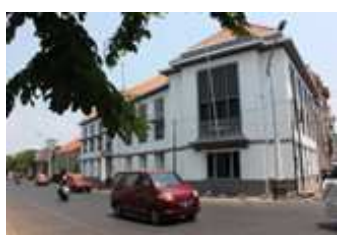

Perkantoran

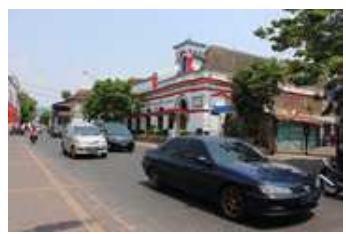

Kantor Telkom

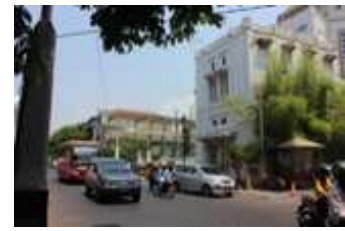

Perkantoran

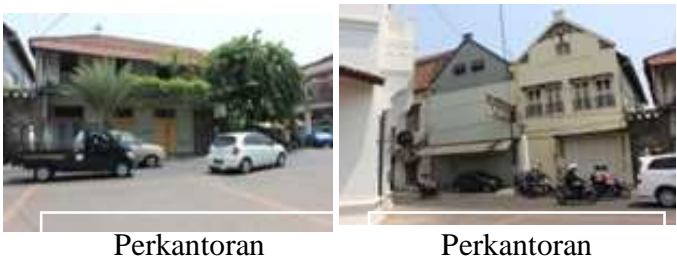

Gambar 2

Kondisi \& fungsi bangunan kolonial dengan karakter asli sisi selatan Jl. Letjen Suprapto Sumber: Penulis (2015)

Kondisi bangunan berkarakter asli kolonial diatas sebagian besar dalam kondisi cukup baik dan terawat. Hal itu dikarenakan fungsi bangunan sebagai fasilitas publik seperti restoran, hotel, perkantoran yang selalu difungsikan setiap harinya sehingga perawatan bangunan terus dilakukan. Namun pada beberapa bangunan ditumbuhi tanaman pada bagian atap/dinding bangunan dikarenakan iklim tropis lembab di Indonesia yang membuat tanaman mudah tumbuh di segala tempat karena kondisi cuaca dan iklim yang mendukung. Selain ditumbuhi tanaman, kerusakan fasade pada bangunan tersebut dapat dilihat dari mengelupasnya cat eksterior bangunan. Hal ini bukanlah disebabkan aksi vandalisme, namun dikarenakan iklim tropis lembab di Indonesia, karena kerusakan cat luar terletak di bagian bangunan yang tidak mudah terjangkau oleh tangan manusia. 


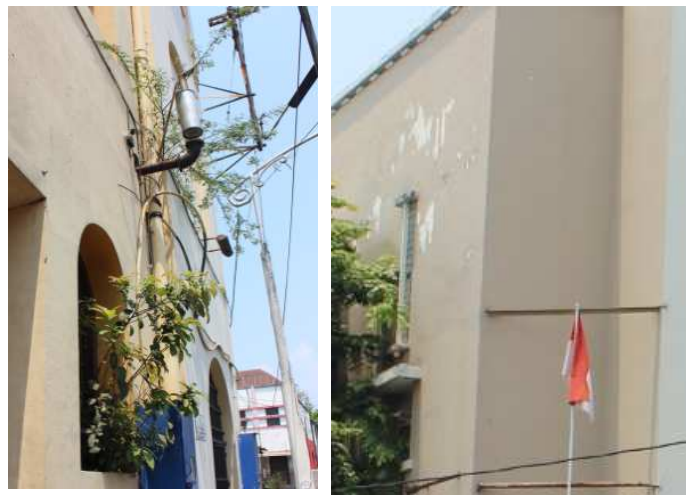

Gambar 3

Kerusakan bangunan difungsikan, karena iklim tropis lembab

Sumber: Penulis (2015)

Pada ruas jalan Letjen Suprapto, terdapat pula bangunan kolonial yang tidak difungsikan. Kondisi bangunan yang tidak difungsikan tersebut buruk dikarenakan tidak adanya perawatan bangunan. Kerusakan fasade bangunan akibat iklim tropis lembabpun juga banyak ditemukan pada bangunan yang tidak difungsikan ini.

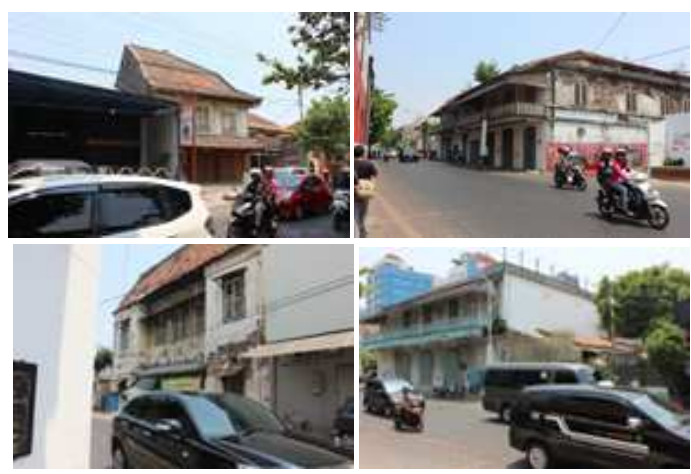

Gambar 4

Kondisi bangunan yang tidak difungsikan Sumber: Penulis (2015)

Kondisi bangunan yang tidak difungsikan di Kota Lama cukup memprihatinkan. Kurangnya perawatan bangunan untuk mengantisipasi dampak iklim tropis lembab menyebabkan mengelupasnya dinding bangunan, ditumbuhinya tanaman-tanaman, dan rusaknya beberapa elemen fasad bangunan. Tumbuhnya tanaman pada fasade bangunan yang tidak difungsikan ini jauh lebih besar dan lebat dikarenakan pembiaran tanaman yang tumbuh di fasade bangunan dalam waktu yang lama. Iklim tropis lembab tanpa perawatan bangunan juga menyebabkan terkelupasnya lapisan dinding bangunan dan kusamnya cat pada fasade bangunan.

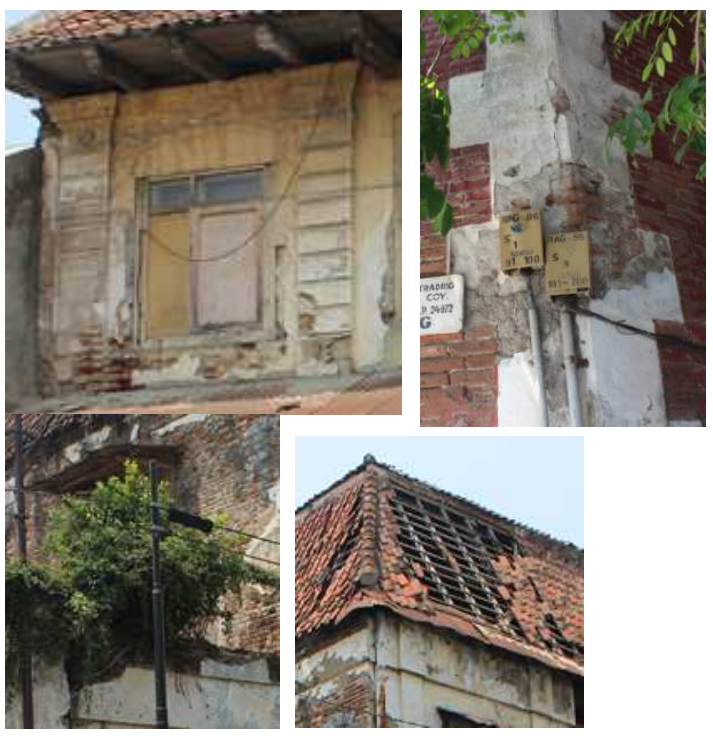

Gambar 5

Kerusakan pada fasade bangunan tidak difungsikan Sumber: Penulis (2015)

- Bangunan yang telah di redesain namun tidak selaras dengan lingkungan Kota Lama Semarang

Pada ruas jalan Letjen Suprapto terdapat bangunan yang telah diredesain dan kini difungsikan. Namun redesain bangunan tersebut tidak selaras dengan lingkungan Kota Lama yang didominasi oleh bangunan Kolonial.

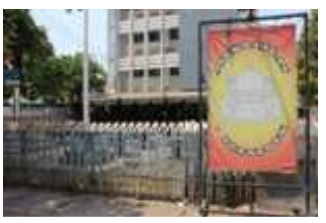

Warung makan "Angkringan"

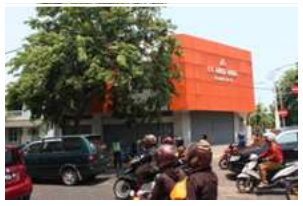

Usaha Pertokoan

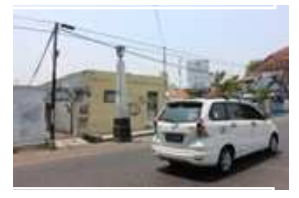

Kantor Polisi

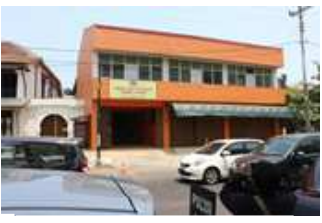

Usaha Pertokoan

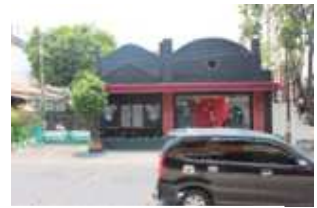

Cafe

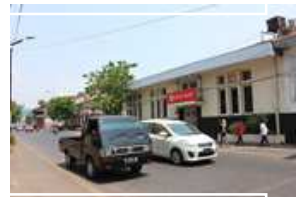

Perkantoran
Gambar 6

Bangunan yang tidak selaras dengan lingkungan Kota Lama Semarang Sumber: Penulis (2015) 
Kondisi bangunan yang diredesain tersebut cukup baik dan tidak ditemui kerusakankerusakan layaknya bangunan kolonial yang difungsikan atau tidak difungsikan. Hal ini dikarenakan bangunan tersebut merupakan bangunan baru dengan perawatan yang rutin karena terus difungsikan sebagai fasilitas publik. Sehingga kerusakan fasade akibat iklim seperti tumbuhnya tanaman, mengelupasnya cat, kusamnya tampak bangunan dapat dihindari.

\section{KESIMPULAN}

Berdasarkan fakta dan analisa dapat diketahui bahwa secara garis besar terdapat 3 kategori bangunan di sepanjang jalan Letjen suprapto:

- Bangunan yang masih berusaha semaksimal mungkin mempertahanklan tampilan fisik arsitektur sesuai aslinya. Contoh marba, Gereja Blenduk, Bank Mandiri.

- Bangunan dengan dominasi arsitektur asli namun sudah banyak perubahan yang tidak memperhatikan keaslian. Contoh: perkantoran di utara Taman Sri Gunting

- Bangunan yang sama sekali baru dengan arsitektur yang tidak selaras dengan lingkungan namun cenderung sangat kontras. Contoh: bangunan di sebelah timur Taman Srigunting.

Berubahnya bangunan dari arsitektur asli disebabkan oleh berbagai hal. Dalam penelitian ini pengamatan hanya dari luar bangunan saja. Hingga hal-hal yang menyebabkan kerusakan bangunan hanya dapat di simpulkan dari kurangnya upaya perawatan hingga elemen yang rusak karena lapuk disebabkan kondisi yang lembab, atau terkena air hujan selama bertahun tahun, tidak segera diatasi dengan perawatan yang memadai atau dengan penggantian elemen yang rusak dengan meterial yanag sama kualitas dan tampilan arsitekturnya.

Tindakan perawatan dengan mencabut tanaman yang tumbuh seharusnya secara teratur dilaksanakan, karena sebenarnya tidak memerlukan biaya besar tetapi memerlukan perhatian yang serius. Karena akar tanaman jelas akan dapat merusak dinding atau kusen.

\section{REKOMENDASI}

Meskipun sudah di tetapkan peraturan untuk bangunan yang dinyatakan sebagai cagar alam atau bangunan yang dilindungi, sudah selayaknya pemerintah juga memperhatikan kemampuan dari pemilik bangunan untuk biaya perawatan bangunan. Dengan demikian pemerintah kota seharusnya mengadakan audiensi pada pemilik bangunan yang tidak sangggup melaksanakan perbaikan untuk mendapat solusi yang tepat.

Usaha untuk memfungsikan bangunan dengan melaksanakan aktifitas yang profit oriented dalam bangunan antara lain restoran ikan bakar Cianjur, Spiegel Bar dan Bistro dapat menjadi contoh untuk bangunan lain yang tidak difungsikan. Mengingat usaha untuk mencari solusi agar bangunan dengan arsitektur asli di sepanjang jalan Letjen Suprapto merupakan usaha untuk mempertahankan citra kota lama sebagai tujuan wisata, sehingga magnet wisatawan tidak hanya Gereja Blenduk dan Taman Sri Gunting yang telah dikelola dengan baik, tetapi juga bangunan lainnya agar fungsi kota lama sebagai magnet untuk wisatawan dan salah satu icon kebanggaan Kota Semarang tidak menurun tetapi justru akan dapat semakin meningkat kualitas dan kuantitasnya

\section{UCAPAN TERIMA KASIH}

Penulis mengucapkan terima kasih pada pihak-pihak yang telah mendukung penulisan artikel ini terutama masyarakat di kota lama yang telah memberikan informasi, sehingga penelitian dapat diselesaikan dan dipublikasikan guna memberi tambahan pengetahuan dalam ilmu arsitektur tropis

\section{DAFTAR PUSTAKA}

Jonki Tio, 2012. Kota Semarang Dalam kenangan. Semarang.

Purwanto LMF. 1996. Adaptasi Arsitektur Kolonial Belanda terhadap Iklim Tropis Lembab Semarang. Tesis S2. Tidak dipublikasikan.

Rapoport, Amos. 1969. House Form and Culture. Englewood Cliffs. N.J.:Prentice Hall 
Sari, Sri Murdiati R.P. 2015. Kawasan Kota Lama Semarang, Identifikasi Step Pelestarian Kawasan. Universitas Sebelas Maret.

Widiastuti, Eko H. 2014. Revitalisasi Benda Cagar Budaya di Kota Semarang. Fakultas Pendidikan IImu Pengetahuan Sosial, IKIP Veteran Semarang.

Sumber lain:

Budaya,Rimanews.com pada 15 Agustus 2014. http://budaya.rimanews.com/peradabansejarah/read/20140815/167770/8-Gedungdi-Kota-Lama-Semarang-Ambruk-
Kompas.com pada 25 Desember 2015. http://regional.kompas.com/read/2015/12/ 25/17541841/Gedung.De.Locomotief.Hanc ur.Gubernur.Ganjar.Akui.Pengelolaan.Kota. Lama.Semarang.Rumit

SindoNews.com pada 25 November 2013. http://daerah.sindonews.com/read/809532 /22/gedung-tua-di-kota-lama-semarangroboh-1-tewas-1385301747 